\title{
Ricos y pobres. La desigualdad económica en España. Madrid. Julio Carabaña. La Catarata, 2016
}

\author{
Joaquín Azagra \\ Universidad de Valencia \\ joaquin.azagra@uv.es
}

En las ciencias, y no sólo en las sociales, una pregunta pertinente y bien planteada es por sí misma, todo un proyecto de investigación. El libro de Julio Carabaña parte de ese tipo de preguntas: ¿Es cierto que la desigualdad ha crecido tanto que lastra el crecimiento? ¿Lo ha hecho tanto como para decir que es más elevada que nunca? Son preguntas oportunas porque casi de golpe, se ha extendido la idea, avalada además por prestigiosos nombres, de que la desigualdad es el primer problema del globalizado sistema económico. Y no siempre tales proposiciones tienen el soporte empírico exigible para cuestionar interpretaciones tan asentadas como las de Marx o de Solow, por ejemplificar posiciones distantes.

Carabaña parte del dato y del rigor en su tratamiento. En su primer capítulo explica al detalle las fuentes utilizadas, valora y compara los datos de autores que le han precedido en su uso y plasma en cuadros bastante claros (quizás algún gráfico hubiese resultado más expresivo y ligero que tantas tablas) la magnitud de los cambios en la desigualdad en el medio plazo. De ellos deduce afirmaciones de calado: En primer lugar, la de que no hay una relación evidente entre el ciclo y la evolución de la desigualdad. Ha crecido en las dos últimas crisis (la breve pero intensa del 93-94 y la actual, desde el 2008) pero disminuyó en la de los 70 (crisis del petróleo). Por su parte, la fase alcista la ha visto disminuir desde la segunda mitad de los 80 , pero estancarse durante el fuerte auge de los primeros años del siglo xxı. No es nuevo el desvincular la evolución de la desigualdad respecto del ciclo económico, pero añade evidencia empírica a quienes sostienen que una sociedad más rica no tiene por qué ser una sociedad más igualitaria.

Sin salir del primer capítulo, destacaré como muy pertinente otra de sus conclusiones: Coinci- diendo con tantos autores, en el intenso aumento de la desigualdad durante la crisis, el nivel actual, cercano al 0.35 , no supera al alcanzado en la anterior crisis del 94 y no llega a los registros de principios de los 80, con un Gini de 0.36, calculado por Alcaide (2004). No es tema menor. Sobre todo, y es la tercera conclusión que quisiera destacar del primer capítulo, cuando se advierte en las tablas (distribución de la renta disponible) y 3 (cuotas de renta en percentiles superiores e inferiores) que la mayor parte del aumento de la desigualdad durante la crisis, deriva de las pérdidas en la primera decila, la más pobre, en tanto que la más alta 0 rica, permanece estable, aunque con ligero aumento, en torno al $24.5025 \%$ en cuanto a captación de renta por ese $10 \%$ más rico. La desigualdad en gran medida se debe a la ampliación del espacio de la pobreza.

Eso conecta con el segundo capítulo, el cual se centra en la renta de los pobres. En este caso, ya no es el objetivo, concretar la desigualdad sino averiguar cuánta gente se sitúa por debajo del umbral de la pobreza. Para ello, recurre al concepto de "pobreza anclada", o sea a "anclar" los respectivos umbrales de renta y actualizarlos en moneda constante. Así observa el brusco incremento de los pobres en el primer envite de la crisis cuyas rentas no sólo descienden sino que en el caso de los muy pobres, se tornan en negativas. Aquí reside otra de las conclusiones nodales del trabajo. Puesto que sólo pueden declarar rentas negativas los trabajadores por cuenta ajena, parece evidente que uno de los componentes básicos del aumento de la pobreza y también de la desigualdad sería el número de autónomos y pequeños empresarios que declaran tales rentas negativas. Ya lo había visto F. J. Goerlich (2016), aunque sin la rotundidad con que se manifiesta Carabaña que llega a cerrar su libro subrayando que "sin los datos nunca 
habría pensado que los pobres que aumentaban y se hacían cada vez más pobres no eran sólo asalariados, sino también empresarios" (pág. 176). Ambos autores coinciden además en registrar un trasvase de clases medias hacia las capas más bajas de la sociedad.

El segundo componente del incremento de la pobreza, lo constituye el desempleo. Los parados son el gran grupo de perjudicados y como entre ellos, hay muchos inmigrantes, ya tenemos la explicación del aumento de la pobreza: parados, inmigrantes y autónomos. Sorprende que no haya una referencia explícita a los working poors, aunque sólo fuera por haberse convertido en tema de moda con el deterioro salarial y contractual de tantos trabajadores por cuenta ajena. Pero en apoyo del autor, que observa cómo entre los pobres no es significativo el número de ocupados por cuenta ajena, diré que una cosa es que haya aumentado el peso de trabajadores precarios entre la población ocupada y otra que lo haya hecho en el espacio de la pobreza. Aquí su peso porcentual ha disminuido bien que por la ampliación de su espacio. Quiero decir, que no es contradictorio el hecho de haber aumentado el trabajo precario con el de su menor contribución al aumento de la pobreza. De lo contrario, los datos sobre el conjunto de asalariados lo delatarían más claramente y los asalariados no son en cualquier caso, según el desglose de los datos que hace el autor, protagonistas del aumento de la pobreza. Con todo, sigo pensando que la cuestión del "precariado" hubiese merecido alguna reflexión suplementaria.

De algún modo, estos análisis alteran la fisonomía de la pobreza, o mejor de su percepción habitual. Conecta directamente con el capítulo 4. ${ }^{\circ}$, en el cual se analiza la contribución a la desigualdad y a la pobreza, de diversas categorías socio-ocupacionales. Ya se ha aludido antes al peso de inmigrantes, parados y ocupados por cuenta propia. Repetiré que los nativos ocupados por cuenta ajena no son significativos en el aumento de la desigualdad ni en el de la pobreza, ni siquiera tras la crisis. Como tampoco lo son los jubilados, fenómeno por otra parte ya conocido.

La misma metodología sirve para detectar a los muy ricos, entre los que destacan los empleados por cuenta ajena, que superan ampliamente a los empresarios. Bien, es posible pero aquí las fuentes pueden resultar decisivas porque en realidad no captan la riqueza, sino la renta, o sea un flujo que aquí se observa con carácter anual. Me caben dudas al respecto. No del análisis de los datos que evidencia esa mayoría de asalariados, sí de la capacidad de las fuentes para detectar los ingresos reales no vinculados a las nóminas. Lo cual no cuestiona el análisis puesto que si el tramo de los muy ricos, se define a partir de los 41991 euros, en moneda constante de 2013 (pág. 83), es obvio que integra sobre todo salarios altos de ejecutivos y sueldos de altos funcionarios, pero también de técnicos e incluso de capataces o trabajadores cualificados. Beneficios empresariales o rentas de propiedad quedan diluidas cuando no ocultas, en estas fuentes.

Es relevante el apunte porque he saltado conscientemente el capítulo $3 .^{\circ}$, donde Carabaña hace una propuesta concreta para mejorar la desigualdad y resolver el problema de la pobreza severa. Consiste en transferir dos puntos de renta de las decilas altas a las dos más bajas. Por vía fiscal, claro. A fin de cuentas, sostiene el autor, en los años de crisis se ha aumentado la presión fiscal en dos puntos de PIB sin aparente fractura de los equilibrios básicos. Eso sí, con la condición de que fuese algo así como un impuesto finalista, destinado directamente a mejorar la situación de quienes se hallan por debajo de la línea de la pobreza.

En este punto se echa algo de menos una mayor explicación. Porque no parece que la vía de elevar los tipos marginales de los altos ingresos, es decir los de sectores de las clases medias, no lo olvidemos, vaya a ser fácil y popular. Las limitaciones del IRPF al respecto son conocidas por más que ya es hora de plantear reformas al respecto. Desde luego, dos puntos de PIB podrían conseguirse a través del IVA, pero en ese caso no sería la redistribución la que definiera el proceso. ¿Tal vez un impuesto a la riqueza? No es idea descabellada. Coinciden el afamado Piketty y el muy conservador FMI que el pasado año recomendó este impuesto. Incluso, 25 ricos franceses - presidentes de firmas como Volvo, Air France, Danone, KLM, Peugeot-Citröen 0 Arnault, la cuarta fortuna mundial— que ofrecían hacerse cargo de un impuesto razonable para que 
no provocase ni fuga de capitales ni evasión fiscal. Pero los ricos no parecen estar por la labor. Que le pregunten a Hollande acerca del resultado de su intentona: 6000 millonarios franceses con domicilio fiscal en Bélgica, 2000 en Suiza...

Porque la desigualdad sí es un problema, más allá de si está o no en un punto soportable 0 intolerable. Hace bien Carabaña en cuestionar adjetivos a veces desaforados, pero no hay que olvidar que si los índices coinciden en la acusada desigualdad actual, el hecho de que no sea mayor que a principios de los 80 no significa que estemos igual sino que hemos retrocedido a una época en que la renta per cápita era mucho menor y ni siquiera se había desplegado en España el Estado del Bienestar. Cierto que en la breve pero intensa crisis del 93-94, volvió a repuntar la desigualdad y para entonces sí existía un sistema de protección social más acabado. Quizás sería oportuno preguntarse si fue él una causa de que aquella crisis se remontase tan rápidamente y sin fractura social. Si fuese así, se- ría oportuno ahora cuestionar la capacidad redistributiva actual del sistema. La sospecha de que los recortes han hecho saltar muchas costuras le resta capacidad de generar cohesión social y deslegitima la política.

De ahí que insista en que la desigualdad sí es un problema. En una sociedad rica, la pobreza severa es un problema con soluciones. Tal vez en el futuro vía renta básica universal, pero desde luego con el actual sistema de rentas mínimas de inserción condicionadas y las ayudas a la dependencia, habría instrumentos para solucionarlo. Claro, con una sustancial ampliación de las dotaciones existentes que no llegan siquiera a representar un punto de PIB y con una mejor gestión, que evite tardanzas burocráticas. Pero la desigualdad no y ésta destruye la cohesión social. La crisis ha mostrado la insuficiencia de la capacidad redistributiva del sistema y asentado la sensación de que urgen reformas. Reformas en la recaudación, pero también en la gestión. 